(2) Open Access Full Text Article

REVIEW

\title{
Daptomycin: an evidence-based review of its role in the treatment of Gram-positive infections
}

This article was published in the following Dove Press journal:

Infection and Drug Resistance

I5 April 2016

Number of times this article has been viewed

\author{
Armando Gonzalez-Ruiz' \\ R Andrew Seaton ${ }^{2}$ \\ Kamal Hamed ${ }^{3}$ \\ 'Darent Valley Hospital, Dartford, \\ UK; ${ }^{2}$ Queen Elizabeth University \\ Hospital, Glasgow, UK; ${ }^{3}$ Novartis \\ Pharmaceuticals Corporation, East \\ Hanover, NJ, USA
}

Correspondence: Kamal Hamed Novartis Pharmaceuticals Corporation, I Health Plaza, East Hanover, NJ 07936, USA

Tel + I 8627784780

Fax + I 973 78I 5987

Email kamal.hamed@novartis.com

\begin{abstract}
Infections caused by Gram-positive pathogens remain a major public health burden and are associated with high morbidity and mortality. Increasing rates of infection with Grampositive bacteria and the emergence of resistance to commonly used antibiotics have led to the need for novel antibiotics. Daptomycin, a cyclic lipopeptide with rapid bactericidal activity against a wide range of Gram-positive bacteria including methicillin-resistant Staphylococcus aureus, has been shown to be effective and has a good safety profile for the approved indications of complicated skin and soft tissue infections ( $4 \mathrm{mg} / \mathrm{kg} /$ day), right-sided infective endocarditis caused by $S$. aureus, and bacteremia associated with complicated skin and soft tissue infections or right-sided infective endocarditis $(6 \mathrm{mg} / \mathrm{kg} / \mathrm{day})$. Based on its pharmacokinetic profile and concentration-dependent bactericidal activity, high-dose ( $>6 \mathrm{mg} / \mathrm{kg} /$ day) daptomycin is considered an important treatment option in the management of various difficult-to-treat Gram-positive infections. Although daptomycin resistance has been documented, it remains uncommon despite the increasing use of daptomycin. To enhance activity and to minimize resistance, daptomycin in combination with other antibiotics has also been explored and found to be beneficial in certain severe infections. The availability of daptomycin via a 2-minute intravenous bolus facilitates its outpatient administration, providing an opportunity to reduce risk of health care-associated infections, improve patient satisfaction, and minimize health care costs. Daptomycin, not currently approved for use in the pediatric population, has been shown to be widely used for treating Gram-positive infections in children.
\end{abstract}

Keywords: daptomycin, efficacy, Gram-positive infections, high dose, OPAT, safety

\section{Introduction}

Infections caused by Gram-positive pathogens remain common, and resistance to traditional, established antibiotics is increasingly recognized. Daptomycin, a cyclic lipopeptide parenteral antibiotic, exhibits rapid concentration-dependent bactericidal activity against Gram-positive pathogens such as methicillin-resistant Staphylococcus aureus (MRSA). ${ }^{1}$ The in vitro bactericidal activity of daptomycin showed that the minimum inhibitory concentrations (MICs) at which $90 \%$ of clinically relevant Grampositive bacteria tested were inhibited were $\leq 1 \mu \mathrm{g} / \mathrm{mL}$, except for enterococci, for which the MICs were 2-4 $\mathrm{g} / \mathrm{mL} .^{2}$ Daptomycin has a distinct mechanism of action involving the calcium-dependent insertion of the compound into the bacterial cytoplasmic membrane. ${ }^{3,4}$ The interactions with the Gram-positive bacterial surface lead to rapid disruption of the membrane without penetrating into the cytoplasm or causing lysis. ${ }^{5}$ Daptomycin also inhibits the synthesis of protein, DNA, RNA, and lipoteichoic acid, and is effective at all growth phases including the stationary phase. This property 
may be particularly useful in the treatment of indolent and deep-seated infections, such as endocarditis and osteomyelitis, where bacteria may exist within biofilm. ${ }^{5}$

Daptomycin is approved for the treatment of complicated skin and soft tissue infections (cSSTIs) (4 mg/kg/day), right-sided infective endocarditis (RIE) caused by $S$. aureus, and bacteremia associated with cSSTIs or RIE $(6 \mathrm{mg} / \mathrm{kg} /$ day). ${ }^{6}$ Daptomycin is not indicated for the treatment of pneumonia. $^{7}$

Published data on pharmacokinetics, clinical safety and efficacy/effectiveness (including high dose and combination therapy), utility in outpatient parenteral antimicrobial therapy (OPAT), and drug resistance of daptomycin are summarized.

\section{Pharmacokinetics of daptomycin}

Daptomycin's pharmacokinetics has been examined in healthy subjects and in patients in both single- and multipledose studies. Pharmacokinetics is generally linear and time independent at doses up to at least $12 \mathrm{mg} / \mathrm{kg} /$ day administered for 14 days (Figure 1). ${ }^{8}$ Following repeated once-daily doses, steady-state concentrations are achieved by the third dose. The serum half-life of the drug is $8-9$ hours. ${ }^{9}$ Daptomycin is renally excreted, and its systemic clearance in healthy adults is $0.011 \mathrm{~L} / \mathrm{kg} / \mathrm{h} .{ }^{10}$ Dosing must be adjusted for adult subjects who have impaired creatinine clearance. ${ }^{11,12}$ In patients with chronic kidney disease stage 4 (creatinine clearance $<30 \mathrm{~mL} / \mathrm{min}$ ) and in subjects undergoing hemodialysis or peritoneal dialysis, a dosage adjustment of daptomycin is recommended. ${ }^{6,9}$ Daptomycin has a very small volume of distribution of $\sim 0.1 \mathrm{~L} / \mathrm{kg}$. It is distributed primarily to

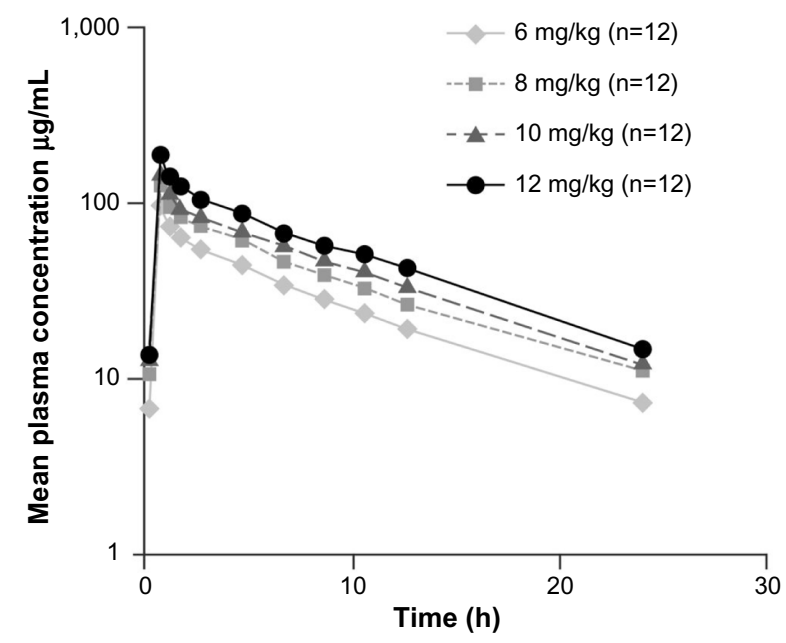

Figure I Plasma daptomycin concentration-time curves at steady state (day 4). Notes: Antimicrob Agents Chemother, 2006;50(I0):3245-3249. DOI: 10.1I28/AAC. 00247-06, ${ }^{8}$ reproduced with permission from American Society for Microbiology. extracellular fluid, does not cross cell membranes, and is $\sim 92 \%$ reversibly bound to serum proteins. ${ }^{9,13}$

Pharmacokinetic studies of daptomycin have been reported in pediatric patients suggesting that higher doses of daptomycin may be required due to increased plasma clearance and hence lower area under the plasma concentration-time curve as compared with adults. ${ }^{14}$ In a recently completed study (NCT00711802) of daptomycin in patients aged 1-17 years with cSSTIs, age-adjusted daptomycin doses were administered once daily to achieve exposures demonstrated to be successful in adult studies of cSSTIs: $12-17$ years, $5 \mathrm{mg} / \mathrm{kg} /$ day; $7-11$ years, $7 \mathrm{mg} / \mathrm{kg} /$ day; 2-6 years, $9 \mathrm{mg} / \mathrm{kg} / \mathrm{day}$; and 1 to $<2$ years, $10 \mathrm{mg} / \mathrm{kg} /$ day. ${ }^{15}$ As described in the 2011 Infectious Diseases Society of America (IDSA) treatment guidelines, high-dose (6-10 $\mathrm{mg} / \mathrm{kg} /$ day) daptomycin may be used in pediatric patients as an alternative drug for the management of MRSA bacteremia, infective endocarditis, acute hematogenous osteomyelitis, and septic arthritis. ${ }^{16}$

As shown in Table 1, the pharmacokinetics of daptomycin has been assessed in specific populations, such as critically ill patients and patients with morbid obesity, moderate hepatic failure and renal disease. ${ }^{11,17-21}$

\section{Safety studies of daptomycin}

Daptomycin has generally been shown to have a good safety profile in several randomized clinical trials (Table 2). ${ }^{22-28}$ In two randomized, controlled, Phase III clinical trials in 1,092 patients with cSSTIs, daptomycin ( $4 \mathrm{mg} / \mathrm{kg} /$ day) therapy was compared with conventional antibiotics such as penicillinaseresistant penicillins. ${ }^{28}$ Daptomycin was well tolerated. The discontinuation rates were low and similar to standard therapy (2.8\% in both groups). The most commonly reported adverse events (AEs) were constipation, nausea, and headache. In an open-label, randomized trial (246 patients) with daptomycin $(6 \mathrm{mg} / \mathrm{kg} /$ day) use in bacteremia and endocarditis, similar overall incidence of AEs was observed in daptomycin and standard therapy groups. ${ }^{27}$ Clinically significant renal dysfunction was lower in patients who received daptomycin as compared to those who received standard therapy $(11.0 \%$ and $26.3 \%$, respectively, $P=0.004$ ).

Post-marketing real-world studies (mainly from large US [CORE] and European [EU-CORE] registries) support the safety of daptomycin and have shown similar findings as the clinical trials. ${ }^{29-35} \mathrm{~A}$ recent systematic review and meta-analysis ${ }^{36}$ showed that the overall incidence of treatment-related AEs was similar between daptomycin and comparator therapy groups. A significantly lower incidence of 
Table I Pharmacokinetics of daptomycin in special populations

\begin{tabular}{|c|c|c|c|}
\hline Authors & Patients & $\begin{array}{l}\text { Daptomycin (dose, } \\
\text { treatment duration) }\end{array}$ & Findings \\
\hline Dvorchik"l & $\begin{array}{l}N=19 \text { with moderate hepatic failure; } \\
\text { aged } \geq 18 \text { years }\end{array}$ & $6 \mathrm{mg} / \mathrm{kg}$ once & $\begin{array}{l}\text { No statistically significant differences in } C_{\max } \\
\text { or AUC were found as compared to healthy } \\
\text { volunteers. Adjustment in daptomycin dose } \\
\text { or dose regimen was not required }\end{array}$ \\
\hline $\begin{array}{l}\text { Dvorchik and } \\
\text { Damphousse }^{18}\end{array}$ & $\begin{array}{l}N=25 \text { patients with morbid obesity; } \\
\text { aged } \geq 18 \text { years }\end{array}$ & $4 \mathrm{mg} / \mathrm{kg}$ once & $\begin{array}{l}C_{\max } \text { and AUC increased by } 25 \% \text { and } 35 \% \text {, } \\
\text { respectively. There was no effect on half-life } \\
\text { and no change in fraction of daptomycin } \\
\text { excreted unchanged in the urine }\end{array}$ \\
\hline Di Paolo et al ${ }^{17}$ & $\begin{array}{l}N=58 \text { with severe Gram-positive infections; } \\
\text { aged } \geq 18 \text { years }\end{array}$ & $4-12 \mathrm{mg} / \mathrm{kg} /$ day, 18 days & $\begin{array}{l}\text { Daptomycin plasma concentrations lower } \\
\text { than that described for healthy volunteers }\end{array}$ \\
\hline Corti et al ${ }^{19}$ & $\begin{array}{l}\mathrm{N}=9 \text { with continuous renal replacement } \\
\text { therapy; aged } \geq 18 \text { years }\end{array}$ & $6 \mathrm{mg} / \mathrm{kg} /$ day, 5 days & $\begin{array}{l}\text { PK of daptomycin similar to healthy } \\
\text { volunteers }\end{array}$ \\
\hline Khadzhynov et $\mathrm{al}^{20}$ & $\begin{array}{l}\mathrm{N}=8 \text { with continuous renal replacement } \\
\text { therapy; aged } \geq 18 \text { years }\end{array}$ & $\begin{array}{l}8 \mathrm{mg} / \mathrm{kg} \text { loading dose followed } \\
\text { by } 4 \mathrm{mg} / \mathrm{kg} \text { every } 48 \text { hours* }\end{array}$ & $\begin{array}{l}\text { PK of daptomycin similar to healthy } \\
\text { volunteers }\end{array}$ \\
\hline Kullar et $\mathrm{a}^{21}$ & $\begin{array}{l}N=160 \text { with renal impairment } \\
(23.8 \% \text { on hemodialysis); aged } \geq 18 \text { years }\end{array}$ & $5.8-7.8 \mathrm{mg} / \mathrm{kg} / \mathrm{day}, 13.5$ days & $\begin{array}{l}\text { Successful outcome observed in } 128(80 \%) \\
\text { patients at the end of daptomycin therapy. } \\
\text { Daptomycin was considered as a safe and } \\
\text { effective therapeutic option in patients with } \\
\text { renal insufficiency }\end{array}$ \\
\hline
\end{tabular}

Note: *Treatment duration is missing.

Abbreviations: AUC, area under plasma concentration-time curve; $C_{\max }$, maximum plasma concentration; $\mathrm{PK}$, pharmacokinetics.

renal impairment, nausea, and headache was observed in the daptomycin therapy group. Elevated creatine phosphokinase (CPK) levels were reported, but these resolved rapidly after the discontinuation of daptomycin therapy. CPK elevation and associated skeletal muscle toxicity were frequently reported in early clinical studies that used multiple daily injections of daptomycin. The use of once-daily injection of daptomycin reduced the risk of this toxicity. ${ }^{2}$ The results from the two clinical Phase III trials showed that elevation in CPK was low (2.1\% with daptomycin and $1.4 \%$ with standard treatment) ${ }^{28}$ Only two patients discontinued daptomycin; one had CPK elevation, and the second had symptoms of muscle toxicity. In another study, patients treated with daptomycin $(6 \mathrm{mg} / \mathrm{kg} /$ day $)$ for endocarditis and bacteremia experienced significantly more CPK elevation compared to standard treatment $(6.7 \%$ vs $0.9 \%, P=0.04) .{ }^{27}$ However, only three patients discontinued daptomycin. The results from real-world clinical experience have shown that a small proportion of patients experienced serum CPK elevation $(<2 \%)$ and severe skeletal muscle toxicity $(0.1 \%){ }^{29}$

As shown in a few studies, high-dose daptomycin may elevate CPK level at an incidence of $2.5 \%-8.3 \% .^{26,37,38}$ However, CPK elevation during daptomycin therapy is not always associated with muscle toxicity. ${ }^{39-42}$ In healthy volunteers, doses up to $12 \mathrm{mg} / \mathrm{kg} /$ day were not associated with muscle toxicity. ${ }^{8}$ In a study on patients treated with high-dose ( $>6 \mathrm{mg} / \mathrm{kg} /$ day) daptomycin, CPK elevations were low $(<3.0 \%) .{ }^{43}$ Concomitant use of daptomycin and statins may increase CPK levels. There was a twofold risk of CPK elevation with concurrent daptomycin and statin therapy as compared to daptomycin alone. ${ }^{44}$ The safety analysis of high-dose daptomycin showed similar rates of CPK elevation in those who received concomitant statin therapy (8\%) as compared to those who did not (10\%). ${ }^{45} \mathrm{CPK}$ levels should be monitored weekly, or more often, in patients with myalgia or concomitant renal failure, or when drugs associated with elevated CPK levels and myopathy are coadministered. ${ }^{46}$

Daptomycin-induced acute eosinophilic pneumonia is a very rare, unpredictable, and potentially serious AE. It should be suspected in the context of fever, hypoxia, and pulmonary infiltrates. ${ }^{47,48}$ These symptoms resolve following the discontinuation of daptomycin; however, supportive therapy, including corticosteroids, may be required. ${ }^{49}$

Although not considered as an AE, apparent prolongation of the prothrombin time may be observed in patients receiving daptomycin due to an interaction with some test reagents, potentially leading to difficulties in therapeutic monitoring for anticoagulation therapy. ${ }^{50}$

\section{Efficacy studies of daptomycin}

Efficacy of daptomycin in patients with cSSTIs, bacteremia, and infective endocarditis caused by $S$. aureus was demonstrated in several randomized, controlled clinical trials (Table 2). Daptomycin (4 mg/kg/day) was compared 


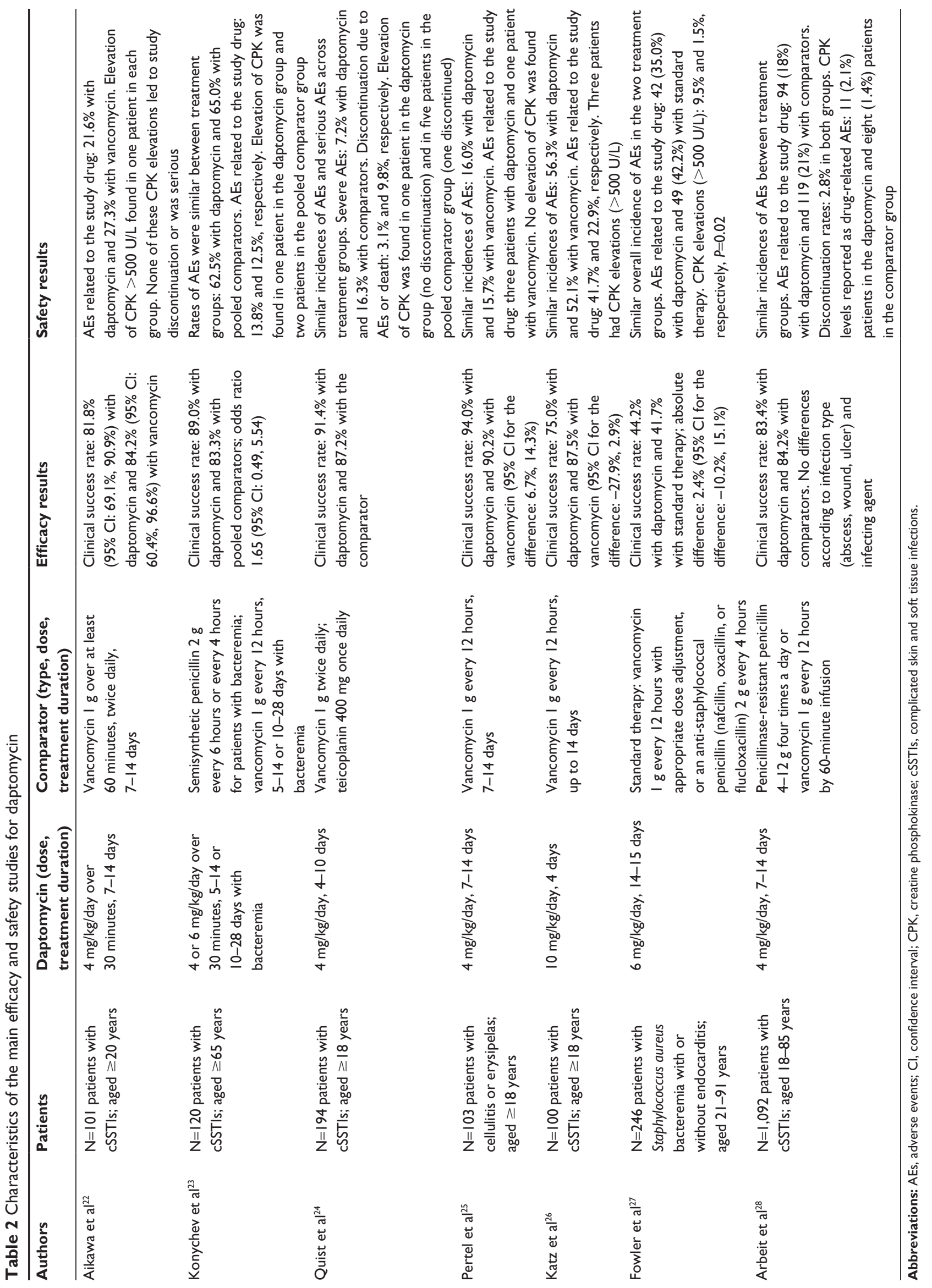


in two randomized double-blind trials with vancomycin or penicillinase-resistant penicillin for the treatment of cSSTIs. ${ }^{28}$ Among 902 evaluated patients, the clinical efficacy of daptomycin was $83.4 \%$ as compared with $84.2 \%$ in the comparator group, and daptomycin required a shorter duration of administration in patients who were successfully treated with intravenous therapy alone. In another study designed to evaluate the efficacy of daptomycin at $6 \mathrm{mg} / \mathrm{kg} /$ day in patients with bacteremia or infective endocarditis caused by $S$. aureus, daptomycin was non-inferior to standard treatment (either vancomycin or an anti-staphylococcal penicillin). ${ }^{27}$ At the request of the Committee for Medicinal Products for Human Use, a comparative study of daptomycin in the elderly population was conducted, which showed that daptomycin had similar efficacy to semisynthetic penicillins and vancomycin in the treatment of cSSTIs. ${ }^{23}$ A recent meta-analysis including 13 randomized controlled trials compared the efficacy of daptomycin with that of comparator therapy. ${ }^{36}$ The results showed that daptomycin was as efficacious as standard therapy in the eradication of pathogens (methicillin-susceptible $S$. aureus, MRSA, Streptococcus pyogenes, Enterococcus faecalis, and Streptococcus pneumoniae), and significantly reduced the intravenous treatment duration.

Clinical trials with rigorous inclusion and exclusion criteria may not reflect true clinical experience. The EU-CORE study provided insight into the real-world clinical experience and supported findings from these clinical trials. ${ }^{29}$ Analyses from the EU-CORE study in patients with various Grampositive infections (cSSTIs, bacteremia, right- and left-sided infective endocarditis, enterococcal infections, foreign body/ prosthetic infections, and osteomyelitis) showed high and consistent rates of effectiveness. ${ }^{29-32,34,35}$

\section{High-dose daptomycin}

In difficult-to-treat infections, on the basis of its pharmacokinetic profile and concentration-dependent bactericidal activity, high-dose ( $>6 \mathrm{mg} / \mathrm{kg} /$ day) daptomycin may be considered due to the potential for more rapid bacterial clearance and reduced risk of emergence of resistance. ${ }^{51,52}$ The IDSA MRSA guidelines recommend consideration of high-dose $(10 \mathrm{mg} / \mathrm{kg} /$ day) daptomycin in patients with persistent MRSA bacteremia associated with vancomycin failure. ${ }^{16}$ Several other national and international treatment guidelines include high-dose $(8-10 \mathrm{mg} / \mathrm{kg} /$ day) daptomycin as a therapeutic option for difficult-to-treat infections including endocarditis, bacteremia, and bone/joint infection. ${ }^{53-55}$ High-dose daptomycin may also be advantageous in patients with sepsis and high volumes of distribution, or when there is a difficulty in achieving adequate local antibiotic concentration at the infection site. ${ }^{56,57}$

Several studies have suggested that higher doses (>6 mg/kg/day) of daptomycin are safe and effective in patients with bacteremia, osteomyelitis, foreign body/ prosthetic infection (mainly orthopedic, intracardiac, and intravascular devices), and endocarditis (Table 3). ${ }^{26,38,43,58-60}$

Clinicians should be cautious when using non-licensed doses of daptomycin in obese patients as they may achieve higher exposure from reduced volume of distribution when compared to nonobese patients. ${ }^{18,61}$

\section{Daptomycin within combination antimicrobial therapy}

In clinical practice, daptomycin is recommended at doses that are higher than those currently approved $(4-6 \mathrm{mg} / \mathrm{kg}$ / day) for the treatment of certain infections (osteomyelitis, foreign body/prosthetic infections, and enterococcal infections). ${ }^{16}$ However, emerging reports of the development of daptomycin resistance ${ }^{62}$ during therapy are cause of concern, and it may be appropriate to consider combination antibiotic therapy in patients at higher risk of developing daptomycin resistance. ${ }^{63}$ Interactions between daptomycin and other antibiotics have been studied in vitro, and it has been shown that activity of gentamicin and rifampicin administered concomitantly with daptomycin was not affected. ${ }^{64-67}$ Other in vitro models demonstrated that the combination of daptomycin and linezolid was synergistic and bactericidal for MRSA and for enterococci. ${ }^{68-70}$ In an in vitro simulated endocarditis pharmacokinetic/pharmacodynamic model, with daptomycin-nonsusceptible MRSA isolates (SA-684 and R6003), daptomycin plus trimethoprimsulfamethoxazole was bactericidal ( 8 hours) and superior to daptomycin alone between 8 and 72 hours $(P<0.001) .{ }^{71}$ In a clinical study, the overall clinical outcome was slightly enhanced with the addition of a $\beta$-lactam; this trend was better for bacteremia associated with endocarditis or bone/ joint infection. ${ }^{72}$

Despite appropriate antimicrobial therapy, bacteremia due to MRSA remains a challenge. ${ }^{73}$ To increase activity and to prevent resistance, high-dose daptomycin used concomitantly with other antimicrobial agents has been considered in treating severe infections and is recommended within IDSA guidelines. ${ }^{16}$ Daptomycin combined with $\beta$-lactams prevents the emergence of resistance to daptomycin in clinical MRSA isolates and in enterococci. ${ }^{64,74-76}$ Mechanistically, $\beta$-lactams increase the negative charge of the bacterial cell 


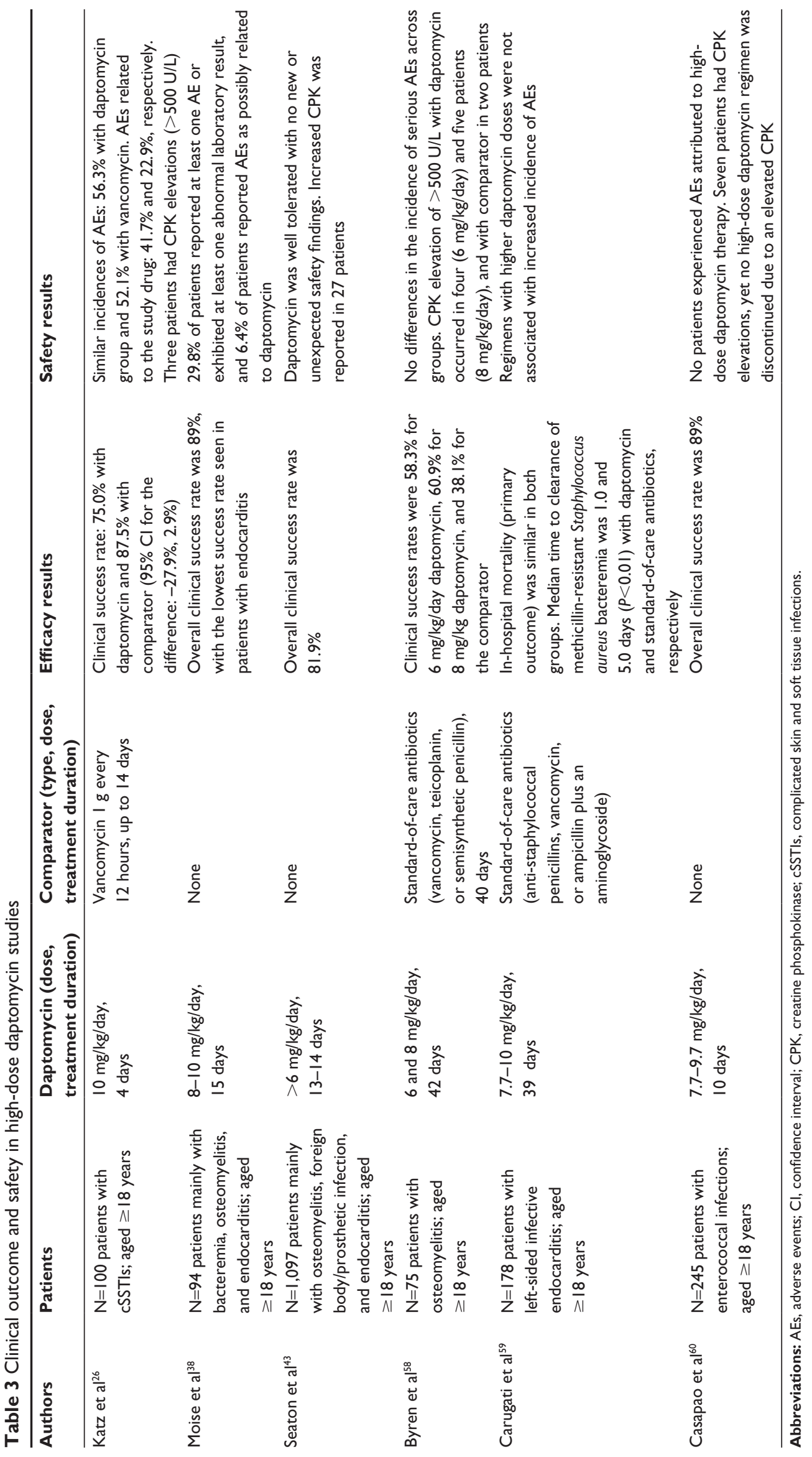


surface leading to a better daptomycin binding and therefore improving its bactericidal activity. ${ }^{77}$ The synergy between daptomycin and $\beta$-lactams leading to bacterial killing and growth inhibition could also be explained by the penicillin-binding protein 1 inactivation following exposure to $\beta$-lactams. ${ }^{78,79}$ Daptomycin has also been used in combination with rifampin, trimethoprim-sulfamethoxazole, fosfomycin, tigecycline, and linezolid in order to achieve the resolution of MRSA infections. ${ }^{80-83} \mathrm{~A}$ combination of high-dose daptomycin and fosfomycin may be effective in the treatment of both native- and prosthetic-valve endocarditis caused by methicillin-susceptible $S$. aureus or MRSA. ${ }^{84}$

\section{Daptomycin use in pediatric patients}

Daptomycin is currently not approved for use in the pediatric population, and appropriate dosages for pediatric patients of different ages are yet to be clearly defined. ${ }^{85}$ A pharmacokinetic study in 25 children (2-17 years of age) receiving $4 \mathrm{mg} / \mathrm{kg} /$ day of daptomycin showed a more rapid clearance in those younger than 6 years. ${ }^{86}$ Another study conducted later showed that use of high-dose $(8-10 \mathrm{mg}$ / $\mathrm{kg}$ /day) daptomycin in children aged 2-6 years provided systemic exposure comparable to that seen in adults treated with the approved daptomycin doses of 4-6 mg/kg/day. ${ }^{87}$ Daptomycin's role in pediatric Gram-positive infections has been evaluated in several studies, and a good safety profile has been observed. ${ }^{9,10,86-89}$ The IDSA MRSA treatment guidelines recommend the use of daptomycin $(6-10 \mathrm{mg} / \mathrm{kg}$ / day) for managing MRSA bacteremia, infective endocarditis, acute hematogenous osteomyelitis, and septic arthritis in pediatric patients. ${ }^{16}$

In a recent multicenter, randomized, Phase III trial that included in total 396 children with cSSTIs, daptomycin given at age-appropriate doses was shown to be efficacious, safe, and generally well tolerated compared with the standard of care. ${ }^{15}$ Results from the EU-CORE registry showed that children and adolescent patients with a variety of Gram-positive infections treated with daptomycin had a high clinical success rate when daptomycin was used as a first- or second-line therapy..$^{90}$

To further investigate the safety and efficacy of daptomycin in pediatric patients aged 1-17 years, a study (NCT01728376) comparing daptomycin to the standard of care for the treatment of $S$. aureus bacteremia was recently completed, and another study (NCT01922011) comparing daptomycin to vancomycin or nafcillin for the treatment of acute hematogenous osteomyelitis is currently ongoing.

\section{Daptomycin use in outpatient practice}

OPAT has been used in many countries to facilitate the costeffective, safe administration of antibiotics as an alternative to an extensive and expensive hospital stay, ${ }^{91,92}$ and to reduce health care-associated infection risk and improve patient satisfaction..$^{93,94}$ The most frequently treated infections in OPAT programs are skin and soft tissue infections (cellulitis, erysipelas, wound infection, and bursitis) and bone and joint infections (discitis, septic arthritis, diabetic foot osteomyelitis, and prosthetic joint and other metalwork-related infections). ${ }^{95}$ Careful attention to risk assessment and management can minimize potential risks in the OPAT setting, ${ }^{96}$ and several national guidelines have been developed to guide service development and patient management. ${ }^{93,97-99}$ Many studies have demonstrated that OPAT is indeed an effective and safe service. ${ }^{100-105}$ The clinical efficacy of OPAT has also been demonstrated for endocarditis or $S$. aureus bacteremia when delivered through a formal service model, ${ }^{106,107}$ and OPAT is now included in European, UK, and US guidelines on the management of endocarditis. ${ }^{108}$

The pharmacokinetic properties of daptomycin allow convenient once-daily 2-minute intravenous injection, ${ }^{6}$ which facilitates outpatient or home administration. ${ }^{95,109}$ This avoids multiple dosing or continuous infusion as required with other available antibiotics. Daptomycin in the OPAT setting is also associated with significantly fewer AEs and antimicrobial interventions compared to vancomycin. ${ }^{110}$ In EU-CORE, 12\% of patients received daptomycin within an OPAT setting with an overall clinical success in $89 \%$ of these patients; the highest clinical success rates were in patients with bacteremia or endocarditis. ${ }^{95}$ Because of its ease of administration and an overall good safety profile, daptomycin has been considered as a first-line agent for use within OPAT. ${ }^{11-113}$

\section{Daptomycin resistance}

Emergence of antibiotic resistance in Gram-positive pathogens has become a major clinical and public health problem worldwide. ${ }^{78,114-116}$ Considering the limited number of new antimicrobial agents, the use of antibiotics in hospitals or elsewhere demands an acute awareness of the increasing problems with resistant organisms. ${ }^{5,62}$ According to the antimicrobial resistance global report on surveillance, antimicrobial resistance has been a growing threat to the effective treatment of an ever-increasing range of bacterial infections. ${ }^{117}$ To assess and monitor the magnitude and trends of the antibiotic resistance problem, major surveillance systems have been implemented. ${ }^{118}$ 
Daptomycin resistance has been previously documented for S. aureus and enterococci. ${ }^{119-123}$ Also, few clinical reports showing emergence of daptomycin resistance have been published until now. The prevalence of de novo resistance to daptomycin without prior exposure has been reported to be extremely rare, showing that only $0.04 \%$ among 10,000 S. aureus isolates tested had an MIC of $2 \mu \mathrm{g} / \mathrm{mL} .{ }^{124}$ The Worldwide Surveillance Programme reported resistance data on daptomycin and numerous comparator agents in 164,457 Gram-positive clinical isolates ( $S$. aureus, coagulase-negative staphylococci, enterococci, hemolytic streptococci) across five continents between 2005 and 2012. The results indicated that daptomycin remained potent against these indicated pathogens. ${ }^{125}$

The mechanisms of daptomycin resistance are multifactorial. ${ }^{74,116,126-128}$ Perturbation of the bacterial cell membrane and overexpression of dltA seem to be considered as the most common factors of resistance. ${ }^{124}$ This dysregulation of dltA transcription may result in a change of the bacterial cell membrane fluidity and therefore lead to a reduced affinity of daptomycin to its target site. ${ }^{129}$ The resistance pathways may vary among Gram-positive organisms. ${ }^{130}$ Mutations in the genes involved in phospholipid synthesis seem to be associated with the development of daptomycin resistance in S. aureus and E. faecalis. ${ }^{130,131}$

\section{Future directions}

Further clinical trials are warranted to better understand how to use high-dose daptomycin, that is, in which patient groups and for which pathogens, and to investigate the utility of short-course regimen. Such trials could provide data on how to minimize the risk of development of resistance and to optimize clinical outcomes. Also, understanding the optimal dosing of daptomycin remains a clinical priority, as well as increasing awareness of the relative benefits of combination therapy. Further research is needed in the form of well-designed, adequately powered trials comparing the efficacy and safety of daptomycin with other new antiGram-positive agents for treating different infections and eradicating pathogens.

Prosthetic joint infection is a devastating and costly complication of arthroplasty. Antibiotic-impregnated cement spacers are a useful tool for facilitating the penetration of the drug into the local infected area. ${ }^{132}$ The first clinical use of daptomycin-impregnated cement was described by Cortes et al who demonstrated a successful treatment in one patient with multiple allergies treated for chronic MRSA hip prosthetic infection. ${ }^{133}$ However, clinical data are lacking, and studies are needed to further evaluate daptomycin's utility in this setting. More generally, implant-associated infection is serious and costly and associated with high morbidity. ${ }^{134}$ The presence of biofilm allows persistence of bacteria in a difficult-to-eradicate physiological state and increases the risk of resistance development. ${ }^{135}$ Further investigation of daptomycin's role within biofilm-related infection is warranted. ${ }^{136}$

\section{Conclusion}

Daptomycin exhibits linear pharmacokinetics at doses up to $12 \mathrm{mg} / \mathrm{kg} /$ day and has been shown to be safe and efficacious for the treatment of cSSTIs, bacteremia, and RIE caused by susceptible Gram-positive bacteria in adults. In addition, according to post-marketing studies, daptomycin is a valuable treatment option in the management of other Gram-positive and difficult-to-treat infections, including left-sided endocarditis, osteomyelitis, prosthetic infections, and enterococcal infections.

On the basis of its pharmacokinetic profile and dosedependent bactericidal activity, higher doses of daptomycin may be beneficial in treating severe infections. High-dose $(>6 \mathrm{mg} / \mathrm{kg} /$ day) daptomycin used in the post-marketing observational studies exhibited a good safety and tolerability profile.

Of particular interest, daptomycin given in combination with other antibiotics may lead to resolution of various complex and resistant Gram-positive infections and may have a role (along with high-dose therapy) in minimizing the development of resistance.

Daptomycin appears promising as a safe and efficacious drug for the treatment of pediatric diseases caused by Grampositive pathogens.

Daptomycin is recognized as an important agent in OPAT practice due to its spectrum of activity and ease of administration.

Although daptomycin resistance has been documented, it remains uncommon.

\section{Acknowledgment}

Medical writing support was provided by Farid Khalfi (Novartis Ireland Ltd, Dublin, Ireland).

\section{Disclosure}

AGR received fees from Novartis, Pfizer, Cubist, and Gilead for staff training, and is a member of advisory boards and speaker panels. RAS received consultancy fees and honoraria for speaking at Novartis-sponsored symposia. KH is 
an employee of Novartis Pharmaceuticals Corporation. The authors report no other conflicts of interest in this work.

\section{References}

1. van Hal SJ, Paterson DL. New Gram-positive antibiotics: better than vancomycin? Curr Opin Infect Dis. 2011;24(6):515-520.

2. Dvorchik BH, Brazier D, DeBruin MF, Arbeit RD. Daptomycin pharmacokinetics and safety following administration of escalating doses once daily to healthy subjects. Antimicrob Agents Chemother 2003;47(4):1318-1323.

3. Nakhate PH, Yadav VK, Pathak AN. A review on daptomycin; the first US-FDA approved lipopeptide antibiotics. J Sci Innov Res. 2013;2(5): 970-980.

4. LaPlante KL, Rybak MJ. Daptomycin - a novel antibiotic against Grampositive pathogens. Expert Opin Pharmacother. 2004;5(11):2321-2331

5. Hancock RE. Mechanisms of action of newer antibiotics for Grampositive pathogens. Lancet Infect Dis. 2005;5(4):209-218.

6. Novartis Europharm Ltd. Cubicin ${ }^{\circledR}$ (daptomycin) summary of product characteristics. 2014.

7. Potashman MH, Formella DN, Hamed K, Mohr JF. Comment on: efficacy and safety of daptomycin for the treatment of infectious disease: a meta-analysis based on randomized controlled trials. J Antimicrob Chemother. 2015;70(4):1274-1275.

8. Benvenuto M, Benziger DP, Yankelev S, Vigliani G. Pharmacokinetics and tolerability of daptomycin at doses up to 12 milligrams per kilogram of body weight once daily in healthy volunteers. Antimicrob Agents Chemother. 2006;50(10):3245-3249.

9. Baietto L, Corcione S, Pacini G, Perri GD, D’Avolio A, De Rosa FG. A 30-years review on pharmacokinetics of antibiotics: is the right time for pharmacogenetics? Curr Drug Metab. 2014;15(6):581-598.

10. Gostelow M, Gonzalez D, Smith PB, Cohen-Wolkowiez M. Pharmacokinetics and safety of recently approved drugs used to treat methicillinresistant Staphylococcus aureus infections in infants, children and adults. Expert Rev Clin Pharmacol. 2014;7(3):327-340.

11. Dvorchik B. Moderate liver impairment has no influence on daptomycin pharmacokinetics. J Clin Pharmacol. 2004;44(7):715-722.

12. Schriever CA, Fernandez C, Rodvold KA, Danziger LH. Daptomycin: a novel cyclic lipopeptide antimicrobial. Am J Health Syst Pharm. 2005;62(11):1145-1158.

13. Estes KS, Derendorf H. Comparison of the pharmacokinetic properties of vancomycin, linezolid, tigecyclin, and daptomycin. Eur J Med Res. 2010;15(12):533-543.

14. Durand C, Brueckner A, Sampadian C, Willett KC, Belliveau P. Daptomycin use in pediatric patients. Am J Health Syst Pharm. 2014;71(14):1177-1182.

15. Glasser C, Agarwal R, Bradley J, Yoon M, Bokesch P. Safety and efficacy of daptomycin in children with complicated skin and skin structure infections (cSSSI) caused by Gram-positive pathogens. Abstract presented at: 33rd Annual Meeting of the European Society for Paediatric Infectious Diseases (ESPID); May 14; 2015; Leipzig.

16. Liu C, Bayer A, Cosgrove SE, et al. Clinical practice guidelines by the Infectious Diseases Society of America for the treatment of methicillinresistant Staphylococcus aureus infections in adults and children: executive summary. Clin Infect Dis. 2011;52(3):285-292.

17. Di Paolo A, Tascini C, Polillo M, et al. Population pharmacokinetics of daptomycin in patients affected by severe Gram-positive infections. Int J Antimicrob Agents. 2013;42(3):250-255.

18. Dvorchik BH, Damphousse D. The pharmacokinetics of daptomycin in moderately obese, morbidly obese, and matched nonobese subjects. J Clin Pharmacol. 2005;45(1):48-56.

19. Corti N, Rudiger A, Chiesa A, et al. Pharmacokinetics of daily daptomycin in critically ill patients undergoing continuous renal replacement therapy. Chemotherapy. 2013;59(2):143-151.

20. Khadzhynov D, Slowinski T, Lieker I, et al. Plasma pharmacokinetics of daptomycin in critically ill patients with renal failure and undergoing CVVHD. Int J Clin Pharmacol Ther. 2011;49(11):656-665.
21. Kullar R, McClellan I, Geriak M, Sakoulas G. Efficacy and safety of daptomycin in patients with renal impairment: a multicenter retrospective analysis. Pharmacotherapy. 2014;34(6):582-589.

22. Aikawa N, Kusachi S, Mikamo H, et al. Efficacy and safety of intravenous daptomycin in Japanese patients with skin and soft tissue infections. J Infect Chemother. 2013;19(3):447-455.

23. Konychev A, Heep M, Moritz RK, et al. Safety and efficacy of daptomycin as first-line treatment for complicated skin and soft tissue infections in elderly patients: an open-label, multicentre, randomized phase IIIb trial. Drugs Aging. 2013;30(10):829-836.

24. Quist SR, Fierlbeck G, Seaton RA, Loeffler J, Chaves RL. Comparative randomised clinical trial against glycopeptides supports the use of daptomycin as first-line treatment of complicated skin and soft-tissue infections. Int J Antimicrob Agents. 2012;39(1):90-91.

25. Pertel PE, Eisenstein BI, Link AS, et al. The efficacy and safety of daptomycin vs. vancomycin for the treatment of cellulitis and erysipelas. Int J Clin Pract. 2009;63(3):368-375.

26. Katz DE, Lindfield KC, Steenbergen JN, et al. A pilot study of high-dose short duration daptomycin for the treatment of patients with complicated skin and skin structure infections caused by gram-positive bacteria. Int J Clin Pract. 2008;62(9):1455-1464.

27. Fowler VG Jr, Boucher HW, Corey GR, et al. Daptomycin versus standard therapy for bacteremia and endocarditis caused by Staphylococcus aureus. $N$ Engl J Med. 2006;355(7):653-665.

28. Arbeit RD, Maki D, Tally FP, et al. The safety and efficacy of daptomycin for the treatment of complicated skin and skin-structure infections. Clin Infect Dis. 2004;38(12):1673-1681.

29. Gonzalez-Ruiz A, Gargalianos-Kakolyris P, Timerman A, et al. Daptomycin in the clinical setting: 8-year experience with Gram-positive bacterial infections from the EU-CORE(SM) registry. Adv Ther. 2015;32(6):496-509.

30. Cogo A, Gonzalez-Ruiz A, Pathan R, Hamed K. Real-world treatment of complicated skin and soft tissue infections with daptomycin: results from a large European registry (EU-CORE). Infect Dis Ther. 2015; 4(3):273-282.

31. Lubbert C, Rodloff AC, Hamed K. Real-world treatment of enterococcal infections with daptomycin: insights from a large European registry (EU-CORE). Infect Dis Ther. 2015;4(3):259-271.

32. Keil F, Daikos GL, Skoutelis A, Dominguez JI, Pathan R, Hamed K. Daptomycin for Gram-positive infections in patients with neutropenia: clinical experience from a European outcomes registry. Adv Ther. 2015;32(8):715-726.

33. Mohr JF, Friedrich LV, Yankelev S, Lamp KC. Daptomycin for the treatment of enterococcal bacteraemia: results from the Cubicin Outcomes Registry and Experience (CORE). Int J Antimicrob Agents. 2009;33(6):543-548.

34. Malizos K, Sarma J, Seaton RA, et al. Daptomycin for the treatment of osteomyelitis and orthopaedic device infections: real-world clinical experience from a European registry. Eur J Clin Microbiol Infect Dis. 2016;35(1):111-118.

35. Guleri A, Utili R, Dohmen P, et al. Daptomycin for the treatment of infective endocarditis: results from European Cubicin ${ }^{\circledR}$ Outcomes Registry and Experience (EU-CORE). Infect Dis Ther. 2015;4(3): 283-296.

36. He W, Zhang Y, Chen H, Zhao C, Wang H. Efficacy and safety of daptomycin for the treatment of infectious disease: a meta-analysis based on randomized controlled trials. J Antimicrob Chemother. 2014;69(12):3181-3189.

37. Figueroa DA, Mangini E, Amodio-Groton M, et al. Safety of high-dose intravenous daptomycin treatment: three-year cumulative experience in a clinical program. Clin Infect Dis. 2009;49(2):177-180.

38. Moise PA, Hershberger E, Amodio-Groton MI, Lamp KC. Safety and clinical outcomes when utilizing high-dose $(>$ or $=8 \mathrm{mg} / \mathrm{kg}$ ) daptomycin therapy. Ann Pharmacother. 2009;43(7):1211-1219.

39. Durante-Mangoni E, Casillo R, Bernardo M, et al. High-dose daptomycin for cardiac implantable electronic device-related infective endocarditis. Clin Infect Dis. 2012;54(3):347-354. 
40. De Rosa FG, Mollaretti O, Cometto C, Pagani N, Montrucchio C, Di Perri G. Early experience with high-dosage daptomycin for prosthetic infections. Clin Infect Dis. 2009;49(11):1772-1773.

41. King EA, McCoy D, Desai S, Nyirenda T, Bicking K. Vancomycinresistant enterococcal bacteraemia and daptomycin: are higher doses necessary? J Antimicrob Chemother. 2011;66(9):2112-2118.

42. Kullar R, Davis SL, Levine DP, et al. High-dose daptomycin for treatment of complicated gram-positive infections: a large, multicenter, retrospective study. Pharmacotherapy. 2011;31(6): 527-536.

43. Seaton RA, Menichetti F, Dalekos G, et al. Evaluation of effectiveness and safety of high-dose daptomycin: results from patients included in the European Cubicin ${ }^{\circledR}$ Outcomes Registry and Experience. Adv Ther. 2015;32(12):1192-1205.

44. Berg ML, Estes LL, Dierkhising RA, Curran B, Enzler MJ. Evaluation of impact of statin use on development of CPK elevation during daptomycin therapy. Ann Pharmacother. 2014;48(3): 320-327.

45. Parra-Ruiz J, Duenas-Gutierrez C, Tomas-Jimenez C, LinaresPalomino JP, Garrido-Gomez J, Hernandez-Quero J. Safety analysis of high dose $(>6 \mathrm{mg} / \mathrm{kg} /$ day $)$ daptomycin in patients with concomitant statin therapy. Eur J Clin Microbiol Infect Dis. 2012;31(8):1771-1774.

46. Hair PI, Keam SJ. Daptomycin: a review of its use in the management of complicated skin and soft-tissue infections and Staphylococcus aureus bacteraemia. Drugs. 2007;67(10):1483-1512.

47. Kim PW, Sorbello AF, Wassel RT, Pham TM, Tonning JM, Nambiar S. Eosinophilic pneumonia in patients treated with daptomycin: review of the literature and US FDA adverse event reporting system reports. Drug Saf. 2012;35(6):447-457.

48. Miller BA, Gray A, Leblanc TW, Sexton DJ, Martin AR, Slama TG. Acute eosinophilic pneumonia secondary to daptomycin: a report of three cases. Clin Infect Dis. 2010;50(11):e63-e68.

49. Patel JJ, Antony A, Herrera M, Lipchik RJ. Daptomycin-induced acute eosinophilic pneumonia. WMJ. 2014;113(5):199-201.

50. White B, Seaton RA. Complicated skin and soft tissue infections: literature review of evidence for and experience with daptomycin. Infect Drug Resist. 2011;4:115-127.

51. Wu G, Abraham T, Rapp J, Vastey F, Saad N, Balmir E. Daptomycin: evaluation of a high-dose treatment strategy. Int J Antimicrob Agents. 2011;38(3):192-196.

52. Bassetti M, Nicco E, Ginocchio F, Ansaldi F, de Florentiis D, Viscoli C. High-dose daptomycin in documented Staphylococcus aureus infections. Int J Antimicrob Agents. 2010;36(5):459-461.

53. Garau J, Bouza E, Chastre J, Gudiol F, Harbarth S. Management of methicillin-resistant Staphylococcus aureus infections. Clin Microbiol Infect. 2009;15(2):125-136.

54. Gudiol F, Aguado JM, Pascual A, et al. [Consensus document for the treatment of bacteremia and endocarditis caused by methicillinresistant Staphylococcus aureus. Sociedad Española de Enfermedades Infecciosas y Microbiología Clínica]. Enferm Infecc Microbiol Clin. 2009;27(2):105-115. Spanish.

55. Mensa J, Barberan J, Llinares P, et al. Guía de tratamiento de la infección producida por Staphylococcus aureus resistente a meticilina [Guidelines for the treatment on infections caused by methicillin-resistant Staphylococcus aureus]. Rev Esp Quimioter. 2008;21(4):234-258. Spanish.

56. Falcone M, Russo A, Venditti M, Novelli A, Pai MP. Considerations for higher doses of daptomycin in critically ill patients with methicillin-resistant Staphylococcus aureus bacteremia. Clin Infect Dis. 2013;57(11):1568-1576.

57. Gould IM, Miro JM, Rybak MJ. Daptomycin: the role of high-dose and combination therapy for Gram-positive infections. Int J Antimicrob Agents. 2013;42(3):202-210.

58. Byren I, Rege S, Campanaro E, et al. Randomized controlled trial of the safety and efficacy of Daptomycin versus standard-of-care therapy for management of patients with osteomyelitis associated with prosthetic devices undergoing two-stage revision arthroplasty. Antimicrob Agents Chemother. 2012;56(11):5626-5632.
59. Carugati M, Bayer AS, Miro JM, et al. High-dose daptomycin therapy for left-sided infective endocarditis: a prospective study from the international collaboration on endocarditis. Antimicrob Agents Chemother. 2013;57(12):6213-6222.

60. Casapao AM, Kullar R, Davis SL, et al. Multicenter study of high-dose daptomycin for treatment of enterococcal infections. Antimicrob Agents Chemother. 2013;57(9):4190-4196.

61. Pai MP, Norenberg JP, Anderson T, et al. Influence of morbid obesity on the single-dose pharmacokinetics of daptomycin. Antimicrob Agents Chemother. 2007;51(8):2741-2747.

62. Kaur DC, Chate SS. Study of antibiotic resistance pattern in methicillin resistant Staphylococcus aureus with special reference to newer antibiotic. J Glob Infect Dis. 2015;7(2):78-84.

63. Entenza JM, Giddey M, Vouillamoz J, Moreillon P. In vitro prevention of the emergence of daptomycin resistance in Staphylococcus aureus and enterococci following combination with amoxicillin/clavulanic acid or ampicillin. Int J Antimicrob Agents. 2010;35(5):451-456.

64. Nadrah K, Strle F. Antibiotic combinations with daptomycin for treatment of Staphylococcus aureus infections. Chemother Res Pract. 2011;2011:619321.

65. Steenbergen JN, Mohr JF, Thorne GM. Effects of daptomycin in combination with other antimicrobial agents: a review of in vitro and animal model studies. J Antimicrob Chemother. 2009;64(6):1130-1138.

66. Yang SJ, Xiong YQ, Boyle-Vavra S, Daum R, Jones T, Bayer AS. Daptomycin-oxacillin combinations in treatment of experimental endocarditis caused by daptomycin-nonsusceptible strains of methicillin-resistant Staphylococcus aureus with evolving oxacillin susceptibility (the "seesaw effect"). Antimicrob Agents Chemother. 2010;54(8):3161-3169.

67. Barber KE, Werth BJ, Ireland CE, et al. Potent synergy of ceftobiprole plus daptomycin against multiple strains of Staphylococcus aureus with various resistance phenotypes. J Antimicrob Chemother. 2014;69(11):3006-3010.

68. Parra-Ruiz J, Bravo-Molina A, Pena-Monje A, Hernandez-Quero J. Activity of linezolid and high-dose daptomycin, alone or in combination, in an in vitro model of Staphylococcus aureus biofilm. J Antimicrob Chemother. 2012;67(11):2682-2685.

69. Entenza JM, Giddey M, Vouillamoz J, Moreillon P, Mancini S. Assessment of the in vitro synergy of daptomycin plus linezolid against multidrug-resistant enterococci. J Global Antimicrob Resistance. 2014;2:306-308.

70. Le J, Bookstaver PB, Rudisill CN, et al. Treatment of meningitis caused by vancomycin-resistant Enterococcus faecium: high-dose and combination daptomycin therapy. Ann Pharmacother. 2010;44(12):2001-2006.

71. Steed ME, Vidaillac C, Rybak MJ. Novel daptomycin combinations against daptomycin-nonsusceptible methicillin-resistant Staphylococcus aureus in an in vitro model of simulated endocardial vegetations. Antimicrob Agents Chemother. 2010;54(12):5187-5192.

72. Moise PA, Amodio-Groton M, Rashid M, et al. Multicenter evaluation of the clinical outcomes of daptomycin with and without concomitant beta-lactams in patients with Staphylococcus aureus bacteremia and mild to moderate renal impairment. Antimicrob Agents Chemother. 2013;57(3):1192-1200.

73. Sakoulas G, Moise PA, Casapao AM, et al. Antimicrobial salvage therapy for persistent staphylococcal bacteremia using daptomycin plus ceftaroline. Clin Ther. 2014;36(10):1317-1333.

74. Berti AD, Wergin JE, Girdaukas GG, Hetzel SJ, Sakoulas G, Rose WE. Altering the proclivity towards daptomycin resistance in methicillinresistant Staphylococcus aureus using combinations with other antibiotics. Antimicrob Agents Chemother. 2012;56(10):5046-5053.

75. Mehta S, Singh C, Plata KB, et al. beta-Lactams increase the antibacterial activity of daptomycin against clinical methicillin-resistant Staphylococcus aureus strains and prevent selection of daptomycin-resistant derivatives. Antimicrob Agents Chemother. 2012;56(12):6192-6200.

76. Rose WE, Schulz LT, Andes D, et al. Addition of ceftaroline to daptomycin after emergence of daptomycin-nonsusceptible Staphylococcus aureus during therapy improves antibacterial activity. Antimicrob Agents Chemother. 2012;56(10):5296-5302. 
77. Ortwine JK, Werth BJ, Sakoulas G, Rybak MJ. Reduced glycopeptide and lipopeptide susceptibility in Staphylococcus aureus and the "seesaw effect": taking advantage of the back door left open? Drug Resist Updat. 2013;16(3-5):73-79.

78. Berti AD, Sakoulas G, Nizet V, Tewhey R, Rose WE. beta-Lactam antibiotics targeting PBP1 selectively enhance daptomycin activity against methicillin-resistant Staphylococcus aureus. Antimicrob Agents Chemother. 2013;57(10):5005-5012.

79. Berti AD, Theisen E, Sauer JD, et al. Penicillin binding protein 1 is important in the compensatory response of Staphylococcus aureus to daptomycin-induced membrane damage and is a potential target for beta-lactam-daptomycin synergy. Antimicrob Agents Chemother. 2015;60(1):451-458.

80. Claeys KC, Smith JR, Casapao AM, et al. Impact of the combination of daptomycin and trimethoprim-sulfamethoxazole on clinical outcomes in methicillin-resistant Staphylococcus aureus infections. Antimicrob Agents Chemother. 2015;59(4):1969-1976.

81. Dhand A, Sakoulas G. Daptomycin in combination with other antibiotics for the treatment of complicated methicillin-resistant Staphylococcus aureus bacteremia. Clin Ther. 2014;36(10):1303-1316.

82. Kelesidis T, Humphries R, Ward K, Lewinski MA, Yang OO. Combination therapy with daptomycin, linezolid, and rifampin as treatment option for MRSA meningitis and bacteremia. Diagn Microbiol Infect Dis. 2011;71(3):286-290.

83. Ahmad NM, Rojtman AD. Successful treatment of daptomycinnonsusceptible methicillin-resistant Staphylococcus aureus bacteremia with the addition of rifampin to daptomycin. Ann Pharmacother. 2010;44(5):918-921.

84. Miro JM, Entenza JM, Del Rio A, et al. High-dose daptomycin plus fosfomycin is safe and effective in treating methicillin-susceptible and methicillin-resistant Staphylococcus aureus endocarditis. Antimicrob Agents Chemother. 2012;56(8):4511-4515.

85. Principi N, Caironi M, Venturini F, Pani L, Esposito S. Daptomycin in paediatrics: current knowledge and the need for future research. J Antimicrob Chemother. 2015;70(3):643-648.

86. Abdel-Rahman SM, Benziger DP, Jacobs RF, Jafri HS, Hong EF, Kearns GL. Single-dose pharmacokinetics of daptomycin in children with suspected or proved gram-positive infections. Pediatr Infect Dis J. 2008;27(4):330-334.

87. Abdel-Rahman SM, Chandorkar G, Akins RL, et al. Single-dose pharmacokinetics and tolerability of daptomycin 8 to $10 \mathrm{mg} / \mathrm{kg}$ in children aged 2 to 6 years with suspected or proved Gram-positive infections. Pediatr Infect Dis J. 2011;30(8):712-714.

88. Antachopoulos C, Iosifidis E, Sarafidis K, et al. Serum levels of daptomycin in pediatric patients. Infection. 2012;40(4):367-371.

89. Ardura MI, Mejias A, Katz KS, Revell P, McCracken GH Jr, Sanchez PJ. Daptomycin therapy for invasive Gram-positive bacterial infections in children. Pediatr Infect Dis J. 2007;26(12):1128-1132.

90. Syriopoulou V, Dailiana Z, Dmitriy N, Utili R, Pathan R, Hamed K. Clinical experience with daptomycin for the treatment of Gram-positive infections in children and adolescents. Pediatr Infect Dis J. Epub 2016 Feb 2.

91. Paladino JA, Poretz D. Outpatient parenteral antimicrobial therapy today. Clin Infect Dis. 2010;51 Suppl 2:S198-S208.

92. Williams DN, Baker CA, Kind AC, Sannes MR. The history and evolution of outpatient parenteral antibiotic therapy (OPAT). Int J Antimicrob Agents. 2015;46(3):307-312.

93. Chapman AL, Seaton RA, Cooper MA, et al. Good practice recommendations for outpatient parenteral antimicrobial therapy (OPAT) in adults in the UK: a consensus statement. J Antimicrob Chemother. 2012;67(5):1053-1062.

94. Seaton RA, Barr DA. Outpatient parenteral antibiotic therapy: principles and practice. Eur J Intern Med. 2013;24(7):617-623.

95. Seaton RA, Gonzalez-Ramallo VJ, Prisco V, et al. Daptomycin for outpatient parenteral antibiotic therapy: a European registry experience. Int J Antimicrob Agents. 2013;41(5):468-472.

96. Halilovic J, Christensen CL, Nguyen HH. Managing an outpatient parenteral antibiotic therapy team: challenges and solutions. Ther Clin Risk Manag. 2014;10:459-465.
97. Howden BP, Grayson ML. 5: Hospital-in-the-home treatment of infectious diseases. Med J Aust. 2002;176(9):440-445.

98. Nathwani D, Zambrowski JJ. Advisory group on Home-based and Outpatient Care (AdHOC): an international consensus statement on non-inpatient parenteral therapy. Clin Microbiol Infect. 2000;6(9):464-476.

99. Tice AD, Rehm SJ, Dalovisio JR, et al. Practice guidelines for outpatient parenteral antimicrobial therapy. IDSA guidelines. Clin Infect Dis. 2004;38(12):1651-1672.

100. Esposito S. Outpatient parenteral treatment of bacterial infections: the Italian model as an international trend? J Antimicrob Chemother. 2000;45(6):724-727.

101. Hitchcock J, Jepson AP, Main J, Wickens HJ. Establishment of an outpatient and home parenteral antimicrobial therapy service at a London teaching hospital: a case series. J Antimicrob Chemother. 2009;64(3):630-634.

102. Chapman AL, Dixon S, Andrews D, Lillie PJ, Bazaz R, Patchett JD. Clinical efficacy and cost-effectiveness of outpatient parenteral antibiotic therapy (OPAT): a UK perspective. J Antimicrob Chemother. 2009;64(6):1316-1324.

103. Corwin P, Toop L, McGeoch G, et al. Randomised controlled trial of intravenous antibiotic treatment for cellulitis at home compared with hospital. BMJ. 2005;330(7483):129.

104. Partridge DG, O'Brien E, Chapman AL. Outpatient parenteral antibiotic therapy for infective endocarditis: a review of 4 years' experience at a UK centre. Postgrad Med J. 2012;88(1041):377-381.

105. Matthews PC, Conlon CP, Berendt AR, et al. Outpatient parenteral antimicrobial therapy (OPAT): is it safe for selected patients to selfadminister at home? A retrospective analysis of a large cohort over 13 years. J Antimicrob Chemother. 2007;60(2):356-362.

106. Gould FK, Denning DW, Elliott TS, et al. Guidelines for the diagnosis and antibiotic treatment of endocarditis in adults: a report of the Working Party of the British Society for Antimicrobial Chemotherapy. J Antimicrob Chemother. 2012;67(2):269-289.

107. Barr DA, Semple L, Seaton RA. Outpatient parenteral antimicrobial therapy (OPAT) in a teaching hospital-based practice: a retrospective cohort study describing experience and evolution over 10 years. Int $J$ Antimicrob Agents. 2012;39(5):407-413.

108. Habib G, Hoen B, Tornos P, et al. Guidelines on the prevention, diagnosis, and treatment of infective endocarditis (new version 2009): the Task Force on the Prevention, Diagnosis, and Treatment of Infective Endocarditis of the European Society of Cardiology (ESC). Endorsed by the European Society of Clinical Microbiology and Infectious Diseases (ESCMID) and the International Society of Chemotherapy (ISC) for Infection and Cancer. Eur Heart J. 2009; 30(19):2369-2413.

109. Chakraborty A, Roy S, Loeffler J, Chaves RL. Comparison of the pharmacokinetics, safety and tolerability of daptomycin in healthy adult volunteers following intravenous administration by $30 \mathrm{~min}$ infusion or 2 min injection. J Antimicrob Chemother. 2009;64(1) $151-158$

110. Shrestha NK, Mason P, Gordon SM, et al. Adverse events, healthcare interventions and healthcare utilization during home infusion therapy with daptomycin and vancomycin: a propensity score-matched cohort study. J Antimicrob Chemother. 2014;69(5):1407-1415.

111. Cervera C, Mestres CA. [Daptomycin in outpatient antimicrobial parenteral therapy]. Enferm Infecc Microbiol Clin. 2012;30 Suppl 1:59-63. Spanish.

112. Martone WJ, Lindfield KC, Katz DE. Outpatient parenteral antibiotic therapy with daptomycin: insights from a patient registry. Int J Clin Pract. 2008;62(8):1183-1187.

113. Nathwani D. Developments in outpatient parenteral antimicrobial therapy (OPAT) for Gram-positive infections in Europe, and the potential impact of daptomycin. J Antimicrob Chemother. 2009; 64(3):447-453

114. Patel H, Shah A, Mistry M, Chanda S. In vitro antimicrobial susceptibility study in clinical isolates of streptococci and enterococci. Afr J Microbiol Res. 2011;5:1374-1378. 
115. Ventola CL. The antibiotic resistance crisis: part 1: causes and threats. P T. 2015;40(4):277-283.

116. Garcia-de-la-Maria C, Pericas JM, Del Rio A, et al. Early in vitro and in vivo development of high-level daptomycin resistance is common in mitis group Streptococci after exposure to daptomycin. Antimicrob Agents Chemother. 2013;57(5):2319-2325.

117. WHO. Antimicrobial resistance: global report on surveillance. 2014. Available from: http://www.who.int/drugresistance/documents/ surveillancereport/en/. Accessed April 2016.

118. Brandt C, Makarewicz O, Fischer T, et al. The bigger picture: the history of antibiotics and antimicrobial resistance displayed by scientometric data. Int J Antimicrob Agents. 2014;44(5):424-430.

119. Traczewski MM, Katz BD, Steenbergen JN, Brown SD. Inhibitory and bactericidal activities of daptomycin, vancomycin, and teicoplanin against methicillin-resistant Staphylococcus aureus isolates collected from 1985 to 2007. Antimicrob Agents Chemother. 2009; 53(5):1735-1738.

120. Diederen BM, van Duijn I, Willemse P, Kluytmans JA. In vitro activity of daptomycin against methicillin-resistant Staphylococcus aureus, including heterogeneously glycopeptide-resistant strains. Antimicrob Agents Chemother. 2006;50(9):3189-3191.

121. Krause KM, Renelli M, Difuntorum S, Wu TX, Debabov DV, Benton BM. In vitro activity of telavancin against resistant grampositive bacteria. Antimicrob Agents Chemother. 2008;52(7): $2647-2652$.

122. Lewis JS 2nd, Owens A, Cadena J, Sabol K, Patterson JE, Jorgensen JH. Emergence of daptomycin resistance in Enterococcus faecium during daptomycin therapy. Antimicrob Agents Chemother. 2005;49(4):1664-1665.

123. Munoz-Price LS, Lolans K, Quinn JP. Emergence of resistance to daptomycin during treatment of vancomycin-resistant Enterococcus faecalis infection. Clin Infect Dis. 2005;41(4):565-566.

124. Stefani S, Campanile F, Santagati M, Mezzatesta ML, Cafiso V, Pacini G. Insights and clinical perspectives of daptomycin resistance in Staphylococcus aureus: a review of the available evidence. Int $J$ Antimicrob Agents. 2015;46(3):278-289.

125. Sader HS, Farrell DJ, Flamm RK, Jones RN. Daptomycin activity tested against 164457 bacterial isolates from hospitalised patients: summary of 8 years of a Worldwide Surveillance Programme (2005-2012). Int J Antimicrob Agents. 2014;43(5):465-469.
126. Kelesidis T, Tewhey R, Humphries RM. Evolution of high-level daptomycin resistance in Enterococcus faecium during daptomycin therapy is associated with limited mutations in the bacterial genome. J Antimicrob Chemother. 2013;68(8):1926-1928.

127. Mishra NN, Bayer AS. Correlation of cell membrane lipid profiles with daptomycin resistance in methicillin-resistant Staphylococcus aureus. Antimicrob Agents Chemother. 2013;57(2):1082-1085.

128. Nannini E, Murray BE, Arias CA. Resistance or decreased susceptibility to glycopeptides, daptomycin, and linezolid in methicillinresistant Staphylococcus aureus. Curr Opin Pharmacol. 2010;10(5): $516-521$.

129. Mishra NN, Bayer AS, Weidenmaier C, et al. Phenotypic and genotypic characterization of daptomycin-resistant methicillin-resistant Staphylococcus aureus strains: relative roles of mprF and dlt operons. PLoS One. 2014;9(9):e107426.

130. Tran TT, Munita JM, Arias CA. Mechanisms of drug resistance: daptomycin resistance. Ann NY Acad Sci. 2015;1354:32-53.

131. Humphries RM, Pollett S, Sakoulas G. A current perspective on daptomycin for the clinical microbiologist. Clin Microbiol Rev. 2013;26(4):759-780.

132. Legout L, Senneville E. Periprosthetic joint infections: clinical and bench research. ScientificWorldJournal. 2013;2013:549091.

133. Cortes NJ, Lloyd JM, Koziol L, O’Hara L. Successful clinical use of daptomycin-impregnated bone cement in two-stage revision hip surgery for prosthetic joint infection. Ann Pharmacother. 2013;47(1):e2.

134. Tsaras G, Osmon DR, Mabry T, et al. Incidence, secular trends, and outcomes of prosthetic joint infection: a population-based study, olmsted county, Minnesota, 1969-2007. Infect Control Hosp Epidemiol. 2012;33(12):1207-1212.

135. Arciola CR, Campoccia D, Speziale P, Montanaro L, Costerton JW. Biofilm formation in Staphylococcus implant infections. A review of molecular mechanisms and implications for biofilm-resistant materials. Biomaterials. 2012;33(26):5967-5982.

136. Gbejuade HO, Lovering AM, Webb JC. The role of microbial biofilms in prosthetic joint infections. Acta Orthop. 2015;86(2):147-158.
Infection and Drug Resistance

\section{Publish your work in this journal}

Infection and Drug Resistance is an international, peer-reviewed openaccess journal that focuses on the optimal treatment of infection (bacterial, fungal and viral) and the development and institution of preventive strategies to minimize the development and spread of resistance. The journal is specifically concerned with the epidemiology of antibiotic

\section{Dovepress}

resistance and the mechanisms of resistance development and diffusion in both hospitals and the community. The manuscript management system is completely online and includes a very quick and fair peerreview system, which is all easy to use. Visit http://www.dovepress.com/ testimonials.php to read real quotes from published authors. 